\title{
Analisis Manajemen Risiko Dan Pengendalian Intern Pada Pengadaan Jasa Konstruksi (Studi Kasus Pengadaan Jasa Konstruksi Pada SKPD Di Lingkungan Pemerintah Provinsi Sumatera Barat)
}

\author{
Analysis of Risk Management and Internal Control on Procurement of \\ Construction Services (Case Study of Procurement of Construction Services at \\ SKPD within the Provincial Government of West Sumatra
}

\author{
Elvita Darma \\ Mahasiswa Magister Teknik Sipil Universitas Andalas, Padang \\ Email :elvita_darma@yahoo.com
}

Naskah Masuk : 14-11-2017 Naskah diterima: 21-11-2017～Naskah disetujui: 16-12-2017

\begin{abstract}
This study aims to identify and classify the risks of occur in the implementation of construction services procurement, an analyzed and assess the risks that arise in the procurement process of construction services and obtained the information about internal controls that have been done by the user. The sample of this research is 2 (two) SKPD in West Sumatera Province that is Office of Infrastructure of Road Spatial and Settlement and Water Resources of Management Office. By using FMEA method, the critical risk is obtained which is then analyzed further by using RPN. The study concluded that the presence of risks that occur during the process of procurement of construction services in the environment SKPD in West Sumatra Provincial Government. The main factors causing this risk are can be in some aspects such as intimidation from provider, LSM, law of enforcement officer and boss towards officers/committees of procurement / Pokja ULP. Then on the planning needs of KPA/ PPK and PPTK, the factors causing the risk are seen in some cases such as the procurement budget is not approved, the available budget is not sufficient and the TOR/KAK can not be used as a reference in the activity of implementation. Then, for the implementation stage there are in the late work, the lack of volume, the work can not be completed by the provider, the failure of the work due to natural disaster, and in the post of procurement/maintenance stages the procurement of construction services have not been utilized, Natural disaster occur, and not implemented FHO to work of constructions. Then when viewed the main risk of factors to the recipient of the work committee is the risk associated with the legal apparatus. Risk management and internal control over the procurement of construction services shall be conducted by all parties having an interest in risk control on the procurement of construction services within the SKPD of West Sumatra Province.
\end{abstract}

Keywords: Risks of Management, Internal Control, Procurement of Construction Services, SKPD

West Sumatera Province.

\begin{abstract}
Abstrak
Tujuan penelitian ini untuk mengidentifikasi dan mengklasifikasikan risiko yang terjadi dalam pelaksanaan pengadaan jasa konstruksi, menganalisis dan melakukan penilaian (assessment) terhadap risiko yang timbul dalam proses pengadaan jasa konstruksi serta memperoleh informasi tentang pengendalian intern yang telah dilakukan oleh pengguna. Metode yang digunakan dalam penelitian ini adalah metode FMEA, diperoleh risiko kritis yang kemudian dianalisis lebih lanjut dengan menggunakan RPN. Hasil penelitian melihat ada risiko-risiko yang terjadi selama proses pengadaan jasa konstruksi di SKPD dilingkungan Pemerintah Provinsi Sumatera Barat. Faktor utama penyebab terjadinya risiko adalah intimidasi dari penyedia, LSM, aparat penegak hukum dan atasan terhadap pejabat/panitia pengadaan/Pokja ULP. Pada perencanaan kebutuhan terhadap KPP/PPK dan PPTK, faktor penyebab terjadinya risiko diantaranya anggaran pengadaan tidak disetujui, anggaran yang tersedia tidak mencukupi dan TOR/KAK yang dibuat tidak dapat dijadikan acuan dalam pelaksanaan kegiatan. Pada tahap pelaksanaan ada pada pekerjaan terlambat, kekurangan volume, pekerjaan tidak dapat diselesaikan oleh penyedia kegagalan pekerjaan akibat force majuere (bencana alam), dan pada tahap pasca pengadaan/pemeliharaan
\end{abstract}


yaitu hasil pengadaan jasa konstruksi belum dimanfaatkan, pemeliharaan tidak dilaksanakan, terjadi bencana alam, serta tidak terlaksanakan FHO terhadap pekerjaan kontruksi. Jika dilihat faktor utama risiko terhadap panitia penerima hasil pekerjaan adalah risiko yang berhubungan dengan aparat hukum. Manajemen risiko dan pengendalian intern terhadap pengadaan jasa konstruksi dilakukan oleh seluruh pihak yang memiliki kepentingan terhadap pengendalian risiko pada jasa pengadaan jasa konstruksi dilingkungan SKPD Provinsi Sumatera Barat.

Kata Kunci: Manajemen Risiko, pengendalian Intern, Pengadaan Jasa Konstruksi, SKPD Provinsi Sumatera Barat.

\section{PENDAHULUAN}

Pengadaan Barang dan Jasa Pemerintah adalah kegiatan untuk memperoleh Barang dan Jasa oleh Kementerian, Lembaga, Satuan Kerja Perangkat Daerah, Institusi lainnya yang prosesnya dimulai dari perencanaan kebutuhan sampai diselesaikannya seluruh kegiatan untuk memperoleh Barang/Jasa. Pengadaan Barang/Jasa di K/L/D/I yang bersifat permanen, dapat berdiri sendiri atau melekat pada unit yang sudah ada. Pengadaan Barang dan Jasa yang dilaksanakan terdiri dari pengadaan jasa konsultansi, pengadaan jasa konstruksi, pengadaan barang dan pengadaan jasa lainnya.

Pada proses pelaksanaan pengadaan barang dan jasa khususnya jasa konstruksi sering berpotensi timbulnya risiko-risiko yang dapat berdampak pada hasil pengadaan, potensi terjadinya risiko dapat terjadi pada pihak pengguna maupun pihak penyedia jasa konstruksi.
Terhadap potensi risiko-risiko yang akan terjadi perlu dilakukan analisis sehingga dapat diketahui penyebab terjadinya risiko tersebut. Analisis risiko atau risk analysis dapat diartikan sebagai sebuah prosedur untuk mengenali satu ancaman dan kerentanan, kemudian menganalisanya dan menyoroti bagaimana dampak-dampak yang ditimbulkan dapat dihilangkan atau dikurangi. Analisis risiko juga dipahami sebagai sebuah proses untuk menentukan pengamanan macam apa yang cocok atau layak untuk sebuah sistem atau lingkungan (ISO 1799, “An Introduction To Risk Analysis”, 2012).

Tujuan dari analisis risiko dalam pengadaan jasa konstruksi ini adalah mengurangi risiko yang berpotensi mengakibatkan kerugian, sehingga dengan berkurangnya risiko diharapkan pengadaan jasa konstruksi dapat dilaksanakan sesuai dengan tujuan pengadaan dan pelaksanaannya sesuai dengan yang waktu yang telah direncanakan. Pada Pemerintah Provinsi Sumatera Barat, proses pengadaan barang dan jasa telah 
diproses oleh Kelompok Kerja (Pokja) Unit Layanan Pengadaan (ULP) yang berada pada Biro Pengelolaan Aset Daerah. Pada tahun pada tahun 2015 terdapat 589 paket pengadaan yang diproses oleh Pokja ULP, berdasarkan jenis pengadaan barang/jasa yang diproses ULP terdiri dari 158 paket pengadaan jasa konsultasi, 196 paket pengadaan jasa konstruksi, 199 paket pengadaan barang dan 36 paket pengadaan jasa lainnya. Dari paket tersebut sampai akhir tahun 2015 terdapat 528 paket lelang selesai $(89,64 \%), 5$ paket lelang gagal $(0,85 \%)$ dan 26 paket lelang batal $(4,41 \%)$.

Sedangkan pada tahun 2016 terdapat 581 paket pengadaan yang diproses oleh Pokja ULP, berdasarkan jenis pengadaan barang/jasa yang diproses ULP terdiri dari 199 paket pengadaan jasa konsultasi, 233 paket pengadaan jasa konstruksi, 121 paket pengadaan barang dan 55 pengadaan jasa lainnya. Dari paket tersebut sampai akhir tahun 2016 terdapat 560 paket lelang selesai $(92,11 \%), 3$ paket lelang gagal $(0,49 \%)$ dan 18 paket lelang batal $(2,96 \%)$.

Sedangkan pada tahap pelaksanaan kemungkinan terjadi risiko diantaranya risiko keterlambatan pelaksanaan pekerjaan dan risiko penyedia tidak dapat menyelesaikan pekerjaan sesuai dengan yang diperjanjikan dalam kontrak.

Sedangkan pada tahap pemeliharaan, risiko yang dapat terjadi adalah kerusakan selama masa pemeliharaan dan baru diketahui setelah masa pemeliharaan berakhir, hal ini terjadi karena pengguna (KPA dan PPTK) tidak melakukan pengecekan terhadap hasil pengadaan selama masa berlaku jaminan pemeliharaan, penyedia tidak bersedia memperbaiki pekerjaan karena kerusakan tidak termasuk dalam poin-poin kerusakan yang harus menjadi tanggungjawab penyedia dan lain-lain.

Berdasarkan risiko-risiko tersebut maka penulis tertarik untuk melakukan penelitian terhadap risiko-risiko yang dapat terjadi dalam pengadaan jasa konstruksi dan pengendalian apa yang telah dilakukan oleh pengguna jasa konstruksi pada SKPD di lingkungan Pemerintah Provinsi Sumatera Barat.

\section{TINJAUAN PUSTAKA}

\section{Pengertian manajemen risiko}

Risiko tidak tercapainya suatu tujuan, kegiatan atau program suatu instansi/organisasi tidak hanya terjadi pada sektor bisnis tetapi juga terjadi pada sektor publik. Untuk itu, instansi pemerintah perlu menyelenggarakan manajemen risiko. 
Definisi Manajemen Risiko menurut Enterprise Risk Management - COSO: “A process, effected by an entity's board of directors, management and other personnel, applied in strategy-setting and across enterprise, designed to identify potential events that may affect the entity, and manage risk to be within its risk appetite, to provide reasonable assurance regarding the achievement of entity objectives (COSO)". Defenisi manajemen risiko diatas dapat dijabarkan lebih lanjut berdasarkan kata-kata kunci sebagai berikut:

\section{On Going Process}

Manajemen risiko dilakukan secara terus menerus dan dimonitor secara berkala. Manajemen risiko bukanlah suatu kegiatan yang dilakukan sesekali (on time event)

\section{Effected by People}

Manajemen risiko ditentukan oleh pihakpihak yang berada dilingkungan instansi/organisasi. Untuk lingkungan instansi pemerintah, manajemn rsiiko dirumuskan oleh pimpinan dan pegawai instasi/departemen yang bersangkutan.

\section{Applied In Strategy-Setting}

Manajemen risiko telah disusun sejak dari perumusan strategi instansi/organisasi oleh manajemen puncak instansi/organisasi. Dengan penggunaan manajemen risiko, strategi yang disiapkan disesuaikan dengan risiko yang dihadapi oleh masing-masing bagian/unit dari instansi/organisasi.

\section{Applied Across The Enterprise}

Strategi yang telah dipilih berdasarkan manajemen risiko diaplikasikan dalam kegiatan operasional dan mencakup seluruh bagian unit pada organisasi. Mengingat risiko bagian unit berbeda maka penerapan manajemen risiko berdasarkan penentuan risiko oleh masing-masing bagian.

\section{Designed To Identify Potential Events}

Manajemen risiko dirancang untuk mengidentifikasi kejadian atau keadaan yang secara potensil menyebabkan terganggunya pencapaian tujuan organisasi.

\section{Provide Reasonable Assurance}

Risiko yang dikelola secara tepat dan wajar akan menyediakan jaminan bahwa kegiatan dan pelayanan oleh organisasi dapat berlangsung secara optimal.

\section{Regarding The Achievement Objectives}

Manajemen risiko diharapkan dapat menjadi pedoman bagi instansi/organisasi dalam mencpai tujuan yang telah ditentukan.

Pada pengadaan barang dan jasa, manajemen risiko dapat diartikan sebagai suatu bagian yang tidak terpisahkan dari 
proses yang bertujuan untuk menerapkan initial screening terhadap risk mengidentifikasi potensi risiko yang terkait dengan pengadaan barang dan jasa dan menanggapi risiko tersebut. Ini mencakup kegiatan-kegiatan yang bertujuan untuk memaksimalkan konsekuensi yang terkait dengan peristiwa positif dan meminimalkan dampak kejadian negatif.

\section{Tujuan Manajemen Risiko}

Setiap kegiatan selau memiliki tujuan, dan setiap pelaksanaan kegiatan selalu terdapat risiko, baik itu risiko positif maupun risiko negatif. Untuk itu agar tujuan pelaksanaan pengadaan barang/jasa dapat dicapai, maka perlu dilaksanakan manajemen risiko.

Beberapa ahli seperti Suh \& Han (2003) memiliki pendapat bahwa tujuan manajemen risiko adalah meminimalisir kerugian. Sedangkan menurut Jacobson (2002) tujuan akhir manajemen risiko adalah "memilih pengukuran peringanan risiko, pemindahan risiko dan pemulihan risiko untuk mengoptimalkan kinerja organisasi”. Menurut Darmawi (2006) manajemen resiko dilaksanakan untuk mengurangi, menghindari, mengakomodasi suatu resiko melalui sejumlah kegiatan yang berurutan yaitu (a) identifikasi resiko, mengidentifikasi resiko apa saja yang mungkin terjadi, events dan potential risk status dan mengembangkannya menjadi preliminary risk status, (b) analisa resiko, menganalisa atau mengukur resiko yang mungkin terjadi untuk menentukan prioritas resiko mana yang harus diselesaikan terlebih dahulu dan metode yang digunakan untuk menyelesaikan atau menguranginya, (c) pengendalian resiko, setelah dua langkah diatas dilaksanakan, langkah selanjutnya adalah mengendalikan resiko tersebut dimana ada dua pendekatan dasar dalam pengendalian resiko yaitu pengendalian resiko (risk control) dengan cara menghindari resiko, mengendalikan kerugian, memisahkan kegiatan yang beresiko dan kombinasi dari ketiga cara diatas serta pembiayaan resiko (risk financing). Dari pendapat para ahli diatas dapat disimpulkan bahwa tujuan manajemen resiko adalah untuk memperkecil kemungkinan terjadinya resiko.

Adapun tujuan dilakukan manajemen risiko dalam pengadaan barang/jasa adalah: Melindungi pengguna dari risiko signifikan yang dapat menghambat pencapaian tujuan pengadaan barang/jasa; Memberikan kerangka kerja manajemen risiko yang konsisten atas risiko yang ada pada proses pengadaan barang/jasa; Mendorong menajemen untuk bertindak proaktif 
mengurangi risiko kerugian, menjadikan pengelolaan risiko sebagai tolak ukur dalam pelaksanaan pengadaan; Membangun kemampuan mensosialisasikan pemahaman mengenai risiko dan pentingnya pengelolaan risiko.

\section{Analisis Risiko}

Analisis merupakan perkiraan dari apa yang akan terjadi jika suatu keputusan diambil. Faktor utama dalam memilih teknik analisis resiko adalah tergantung pada tipe dan besar kecilnya nilai pengadaan barang/jasa, informasi yang tersedia, biaya analisis, waktu yang tersedia untuk menganalisis, serta pengalaman dan keahlian analis.(Smith 1999). Secara garis besar ada dua macam cara untuk melakukan analisis resiko, yaitu secara kuantitatif dan kualitatif. Analisis secara kuantitatif digunakan pada hal-hal yang dapat dihitung secara matematis misalnya kerugian materi yang disebabkan adanya pengadaan barang/jasa, sedangkan analisis secara kualitatif digunakan kepada hal-hal yang tidak dapat dihitung secara materi contohnya adalah gangguan kenyamanan pada masyarakat disekitar proyek analisis resiko dapat dilakukan dengan dua cara yaitu, analisis secara kualitatif dan kuantitatif.

\section{Pengendalian Intern}

Pengendalian intern meliputi struktur organisasi, metode dan ukuran-ukuran yang dikoordinasikan untuk menjaga kekayaan organisasi, mengecek ketelitian dan keandalan data akuntansi, mendorong efisiensi dan mendorong dipatuhinya kebijakan manajemen (Mulyadi, 2008:163).

Menurut Peraturan Pemerintah Nomor 60 Tahun 2008 tentang SPIP, pengertian pengendalian internal adalah: "Proses yang integral pada tindakan dan kegiatan yang dilakukan secara terus menerus oleh pimpinan dan seluruh pegawai untuk memberi keyakinan yang memadai atas tercapainya tujuan organisasi melalui kegiatan yang efektif dan efisien, keandalan pelaporan keuangan, pengamanan asset Negara dan ketaatan terhadap peraturan perundang-undangan".

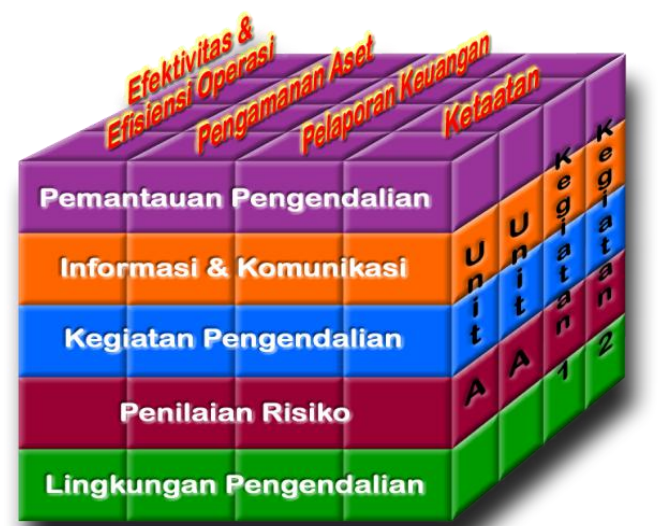

Gambar 2.7. Sistem pengendalian internal pemerintah. 


\section{METODOLOGI}

Data untuk penelitian ini didapatkan dengan melakukan wawancara dan penyebaran kuisioner kepada KPA/PPK/PPTK, Pejabat/Panitia Pengadaan/Pokja ULP dan Pejabat/Panitia Penerima Hasil Pekerjaan pada pengadaan jasa konstruksi yang ditetapkan dengan SK Gubernur Sumatera Barat/ SK yang dikeluarkan oleh Kepala SKPD tahun 2015 dan 2016 di 2 (dua) SKPD dilingkungan Pemerintah Provinsi Sumatera Barat (Dinas Prasjal Tarkim dan Dinas PSDA). Kemudian dilakukan analisis secara kuantitatif dengan langkah-langkah sebagai berikut:

1). Melakukan penyebaran kuisoner untuk menentukan rating probabilitas risiko (occurrence), dampak terjadinya risiko (severity) dan deteksi terjadinya risiko (detection) dari tiap-tiap risiko dengan skala 1 sampai 5 dengan menggunakan metode pembobotan skala Likert's Summated Rating (LSR) berikut ini:

$$
\begin{array}{ll}
\text { occurrence } & \text { severity: } \\
1=\text { tidak pernah } & 1=\text { sangat kecil }(\mathrm{SK}) \\
2=\text { jarang } & 2=\text { kecil }(\mathrm{K}) \\
3=\text { kadang-kadang } & 3=\operatorname{sedang}(\mathrm{S}) \\
4=\text { sering } & 4=\text { besar }(\mathrm{B}) \\
5=\text { selalu } & 5=\text { sangat besar }(\mathrm{SB})
\end{array}
$$

2). Mengetahui tingkat kepentingan resiko digunakan persamaan seperti dibawah ini (Zhi, 1995):

Nilai tingkat kepentingan resiko

$$
\mathrm{a} \times \mathrm{b}=\mathrm{z}
$$

Dimana nilai pada frekuensi $=\mathrm{a}$ $(1-5)$, nilai pada dampak $=b(1-5)$ dan Jumlah Faktor Resiko: z

Tingkat kepentingan resiko secara keseluruhan adalah

$$
(\Sigma \mathrm{ci}) / \mathrm{z}
$$

Untuk mengurutkan resiko hasil perkalian antara skala frekuensi dan dampak, disusun dari yang terbesar hingga yang terkecil yang dapat dikelompokkan berdasarkan tingkat kepentingannya dan memperoleh suatu interval yang menyatakan tingkatan risiko, tinggi, sedang dan rendah seperti tabel dibawah:

Tabel 3.5 Interval Nilai Risiko

\begin{tabular}{|l|l|}
\hline Interval & Nilai Risiko \\
\hline $12-25$ & Tinggi \\
\hline $8-12$ & Sedang \\
\hline $1-8$ & Rendah \\
\hline
\end{tabular}

(Sumber : Suwandi, Putri Anggi Permata, 2012)

3). Menghitung Risk Priority Number (RPN) dengan persamaan matematisnya dapat dinyatakan sebagai berikut: 
$\mathrm{RPN}=(\mathrm{S}) \times(\mathrm{O}) \times(\mathrm{D})$ (Robin, Rayomond dan Michael: 1996)

Suatu risiko dikategorikan pada risiko kritis jika memiliki nilai RPN di atas nilai kritis. Nilai kritis RPN ditentukan dari nilai-nilai RPN dari seluruh risiko.

Nilai kritis $=-\frac{\text { Total RPN }}{\text { Jumlah Resiko }}$

4).Membuat prioritas untuk ditindaklanjuti.

\section{HASIL DAN PEMBAHASAN}

Risiko Pengadaan terhadap Pejabat/Panitia Pengadaan/Pokja ULP

Berdasarkan hasil penelitian dan pengolahan data pada tahap pengadaan terhadap pejabat/panita/pokja ULP menggunakan metode RPN diperoleh 5 risiko kritis terhadap manajemen pengadaan jasa konstruksi di SKPD Provinsi Sumatera Barat dalam hal risiko pengadaan terhadap pejabat/panitia pengadaan. Hal ini disebabkan karena 5 risiko tersebut berada di atas nilai kritis yang dicari, sebab semakin besar nilai RPN yang diperoleh maka risiko tersebut akan berada pada peringkat risiko yang sangat tinggi, demikian pula sebaliknya semakin rendah nilai RPN yang diperoleh maka semakin rendah pula suatu peringkat risiko. Peringkat risiko disusun dengan tujuan agar pemangku risiko atau Pejabat/Panitia Pengadaan beserta anggotanya mengetahui prioritas kesalahan mana yang harus ditangani terlebih dahulu. Adapun 5 risiko yang berada di atas 21,69 adalah tentang terdapatnya monopoli dalam pelelangan memiliki nilai kritis hasil penghitungan adalah 21,69, Lelang gagal/ulang dengan nilai kritis 29.80, Risiko keterlambatan dokumen lelang dari PPK SKPD memiliki nilai kritis 24.40, Intimidasi dari Penyedia, LSM dan aparat penegak hukum nilai kritisnya 39,2 dan Intimidasi dari Atasan/Kepala Daerah memiliki nilai kritis 35, 18 maka tentu saja seluruh hal yang masuk pada nilai kritis ini harus segera mendapatkan perhatian oleh pejabat/panitia pengadaan/pokja di lingkungan SKPD Provinsi Sumatera Barat.

\section{Risiko Pengadaan terhadap KPA/PPK dan PPTK}

Analisis risiko pada pengadaan pengadaan jasa konstruksi di SKPD dilingkungan Pemerintah Provinsi Sumatera Barat dari KPA/PPK dan PPTK dilihat dari tiga hal yaitu dari segi perencanaan kebutuhan/kegiatan, tahap pelaksanaan, dan pasca pengadaan/tahap pemeliharan.

Pada segi perencanaan kebutuhan/kegiatan berdasarkan metode RPN terdapat 4 risiko 
yang berada di atas 16,64 yang merupakan batas nilai kritis. 4 risiko tersebut mencakup pada anggaran yang tersedia tidak mencukupi untuk pengadaan merupa RPN tertinggi yaitu 22,93 dan tertinggi dari batas nilai kritis yaitu sebesar 16,64, kemudian TOR/KAK yang dibuat tidak dapat dijadikan acuan dalam pelaksanaan kegiatan dengan nilai RPN sebesar 20,98. Pengadaan jasa konstruksi tidak masuk dalam Rencana Kebutuhan Barang Milik Daerah (RKBMD) memiliki nilai RPN sebesar 17,21. Kemudian pemecahan / pengabungan pekerjaan yang tidak tepat merupakan risiko terendah karena nilai RPN mendekati batas nilai kritis yaitu 16,88 .

Pada tahap pelaksanaan maka diperoleh 6 risiko kritis karena berada di atas 21 yang merupakan batas nilai kritis. 6 risiko kritis tersebut adalah pada tenaga ahli pada konsultan perencanaan tidak kompeten merupa RPN tertinggi yaitu 39,55, selanjutnya pada pada Personil/Tenaga ahli penyedia tidak memiliki kompetensi dalam pelaksanaan pekerjaan dengan nilai RPN mencapai 38.30. Pada Personil/tenaga ahli dilapangan tidak sesuai dengan personil/tenaga ahli dalam kontrak/tanpa persetujuan pengguna nilai RPN nya
28.30, pekerjaan terlambat dari waktu yang ditetapkan memiliki nilai RPN 22.75, serta berupa Penyedia/Konsultan perencanaan keliru dalam menerjemahkan keinginan pengguna merupakan risiko terendah karena nilai RPN mendekati batas nilai kritis yaitu 21,05 .

Pada tahap Pasca Pengadaan /Tahap Pemeliharaan berdasarkan hasil penelitian yang dilakukan baik melalui hasil pengamatan dan kuisoner diperoleh hasil diperoleh 1 risiko kritis terhadap perencanaan pengadaan jasa konstruksi di SKPD Provinsi Sumatera Barat pada KPA/PPK dan PPTK. Hal ini disebabkan karena 1 risiko tersebut berada di atas nilai kritis yang dicari, yaitu sebesar 20,37 yang merupakan batas nilai kritis. Adapun risiko kritis tersebut terlihat pada terjadi bencana alam selama masa pemeliharaan yang mengakibatkan kerusakan pada konstruksi nilai RPNnya sebesar 35.58 .

\section{Risiko Pengadaan terhadap Panitia Penerima Hasil Pekerjaan}

Berdasarkan perhitungan dengan metode RPN di atas maka diperoleh 1 risiko kritis terhadap manajemen pengadaan jasa konstruksi di SKPD Provinsi Sumatera Barat dalam hal risiko pengadaan terhadap terhadap Panitia Penerima Hasil Pekerjaan. Adapun 1 risiko yang berada di atas 24,89 yang merupakan batas nilai kritis terdapat 
pada risiko berhubungan dengan aparat hukum dengan nilai RPNnya sebesar 36,69 .

\section{Pengendalian Intern yang telah dilaksanakan oleh SKPD}

Pengendalian secara internal dilakukan untuk mengetahui pihak-pihak yang bertanggung jawab dalam menerapkan proses manajemen risiko dan siapa yang menjadi pemangku kepentingan terkait. Berbagai pendekatkan dilakukan untuk mengetahui konteks manajemen yang benar, keahlian setiap pegawai dimiliki untuk menganalisis risiko, memastikan bahwa semua risiko telah diidentifikasi dan perlakuan untuk masing - masing risiko.

Pengendalian secara Internal terhadap KPA/PPK/PPTK dilakukan sesuai dengan kewenangannya dalam pengadaan jasa konstruksi tersebut yang dimulai dari perencanaan, pengadaan, serta pasca pengadaan/pemeliharaan. Kegiatan pengawasan intern dalam perencanaan terhadap KPA/PPK/PPTK pada SKPD Provinsi Sumatera Barat meliputi pada pengawasan pada perencanaan pengadaan jasa konstruksi, rencana pengunaan anggaran, penyusunan dokumen, penyusunan HPS serta rencana pemecahan masalah. Pengawasan intern terhadap kegiatan pelaksanaan jasa konstruksi pada SKPD Provinsi Sumatera Barat meliputi pengawasan pada pengadaan tenaga ahli, pemilihan dan peninjaun lokasi, penentuan barang, menetapkan jenis pekerjaan, melakukan evaluasi serta terakhir adalah mengadakan serah terima. Serta pengawasan intern terhadap kegiatan pasca pengadaan/ pemeliharaan jasa konstruksi pada SKPD Provinsi Sumatera Barat meliputi pengawasan terhadap hasil yang diperoleh, pemanfaatannya serta bagaimana pula pemeliharaannya.

Pengendalian secara Internal terhadap Pejabat/Panitia Pengadaan/Pokja ULP dilakukan dalam rangka pengadaan jasa konstruksi tersebut meliputi pada saat penentuan jenis barang, dalam melakukan lelang serta juga pengawasan terhadap berbagai rintangan yang dihadapi seperti adanya intimidasi dari berbagai pihak, apakah dari pihak penyedia, LSM, Aparat hukum ataupun dari atasan/kepala daerah.

Kemudian pengendalian yang harus dikelola SKPD melalui proses yang sistematis dan terstruktur terutama terhadap panitia penerima hasil pekerjaan dalam rangka pengadaan jasa konstruksi tersebut meliputi pada volume pekerjaan, spesifikasi pekerjaan, serta rintangan dalam menerima barang terutama dalam mengaji bagimana risiko berurusan dengan penegak hukum, serta PHO untuk beberapa paket pekerjaan 
pada tanggal yang sama pada akhir tahun anggaran.

\section{PENUTUP}

\section{Kesimpulan}

Terdapatnya risiko-risiko yang terjadi selama proses pengadaan jasa konstruksi di SKPD dilingkungan Pemerintah Provinsi Sumatera Barat, namun risikorisiko tersebut berdasarkan hasil pengolahan RPN yang dilakukan baru pada tingkat sedang, namun walaupun demikian diperlukan dilakukan pengendalian oleh SKPD di lingkungan Pemerintah Provinsi Sumatera Barat agar risiko sedang tersebut tidak mengarah pada risiko pada tingkat tinggi

Faktor-faktor utama penyebab terjadinya risiko adalah ini dapat pada beberapa aspek hal ini penulis lihat dari nilai kirits yang memiliki nilai RPNnya diatas nilai kritis, diantaranya adalah Intimidasi dari penyedia, LSM, Aparat Penegak hukum dan Atasan terhadap pejabat/panitia pengadaan/Pokja ULP. Kemudian pada perencanaan kebutuhan terhadap KPP/PPK dan PPTK, faktor penyebab terjadinya risiko terlihat pada beberapa hal diantaranya anggaran pengadaan tidak disetujui, anggaran yang tersedia tidaak mencukupi dan TOR/KAK yang dibuat tidak dapat dijadikan acuan dalam pelaksanaan kegiatan. Selanjutnya untuk tahap pelaksanaan terdapat pada pekerjaan terlambat, kekurangan volume, pekerjaan tidak dapat diselesaikan oleh penyedia kegagalan pekerjaan akibat force majuere (bencana alam), dan pada tahap pasca pengadaan/pemeliharaan yaitu hasil pengadaan jasa konstruksi belum dimanfaatkan, pemeliharaan tidak dilaksanakan, terjadi bencana alam, serta tidak terlaksanakan FHO terhadap pekerjaan kontruksi. Kemudian jika dilihat faktor utama risiko terhadap panitia penerima hasil pekerjaan adalah risiko yang berhubungan dengan aparat hukum. Kemudian apakah telah dilakukan manajemen risiko dan pengendalian intern terhadap pengadaan jasa konstruksi tersebut, dalam penelitian ini terjawab telah dilakukan oleh seluruh pihak yang memiliki kepentingan terhadap pengendalian risiko pada jasa pengadaan jasa kontrusksi dilingkungan SKPD Provinsi Sumatera Barat.

\section{Saran}

Pengendalian tambahan terhadap risiko yang akan timbul yang dilakukan berdasarkan hasil penelitian baru dilakukan oleh Pejabat/Panitia Pengadaan, seperti penyusunan jadwal disesuai dengan kebutuhan/typical pekerjaan, meminimalisir addendum dokumen pengadaan/RAB. Memaksimal Aanwijzing penjelasaan pekerjaan dan Adendum dokumen 
pengadaan, untuk pekerjaan komple memberikan wkatu lebih panjang, penyusunan jadwal selogis mungkin sesuai dengan kompleksitas pekerjaan, penyusunan dokumen lelang secara teliti dan sesuai aturan, memberikan honor yang seimbang terhadap panitia pengadaan, penunjukan/SK PPK/KPA sedini mungkin, dokumen lelang dari PPK ke Pokja disampaikan secara lengkap serta tidak memaksakan kehendak untuk menjadi pokja.

\section{DAFTAR PUSTAKA}

Anonim, 2006, Pengertian/Defenisi dari Manajemen, Komunitas \& Perpustakaan Online Indonesia

BPKP, 2014, Manajemen Risiko Integratif

Darmawi.H, 2006, Manajemen Risiko, Bumi Aksara, Jakarta, Indonesia

Dewati et al, 2010, Pembangunan Jalan Tol Lingkar Luar Jakarta (JORR) WI Ruas Kebon JerukPenjaringan Paket $4 \& 5$.

McDermott, Robin E , Raymond J Mikulak, Michael R Beauregard, 2010, The Basics of FMEA, 2nd Edition.

Nainggolan et al, 2010, Manajemen Resiko Kinerja Biaya dan Waktu Proyek Central Park Jakarta.

Peraturan Presiden Nomor 4 Tahun 2015 tentang Perubahan Keempat Peraturan Presiden Nomor 54 Tahun 2010 tentang Pengadaan Barang dan Jasa Pemerintah

Suwandi, Putri Anggi Permata , 2010, Kajian Manajemen Resiko pada Proyek dengan Sistem Kontrak
Lumpsum dan Sistem Kontrak Unit Price (studi kasus pada proyek jalan dan jembatan, gedung, bangunan air)

Waracanova, Sartika Dwi , 2012, Analisis Peranan Audit Internal terhadap Corporate Governance, Manajemen Risiko dan Pengendalian Intern Studi Kasus pada Proyek XYZ 